\title{
Challenging Therapy In Pregnant Woman With Systemic Lupus Erythematosus (SLE) and Chronic Hepatitis B
}

\author{
Choirina Windradi ${ }^{1}$, Awalia $^{2 *}$
}

${ }^{1}$ Faculty of Medicine Universitas Airlangga, Surabaya, Indonesia

${ }^{2}$ Department of Internal Medicine, Faculty of Medicine Universitas Airlangga, Surabaya, Indonesia - Dr. Soetomo General Hospital Surabaya, Indonesia

\section{A R T I C L E I N F O}

\section{Article history:}

Received 15 May 2020

Received in revised form 28 May 2020

Accepted 02 June 2020

Available online 30 June 2020

Keywords:

Systemic lupus erythematosus,

Hepatitis B,

Pregnancy

\section{*) Corresponding author:}

awalia_nov74@yahoo.com

\begin{abstract}
A B S T R A C T
Systemic Lupus Erythematosus (SLE) is an autoimmune disease that attacks various body systems, especially in women of reproductive age. Therefore, patients who are planning a pregnancy or are pregnant need to assess the risk and predicts of disease activity during pregnancy. The most common complications of SLE in pregnancy are SLE disease activity, preterm delivery, preeclampsia and preganancy loss. Here, we report a pregnant SLE patient with co-infection hepatitis B. As the consequence of treated with immunosuppressant agent, both disease progression and immunosupressant agent can lead to severe infection. Furthermore, perinatal transmission is the most common form of transmission of hepatitis B. Finally, proper management could save mother and newborn.
\end{abstract}

\section{Introduction}

Systemic Lupus Erythematosus (SLE) is an autoimmune disease predominantly affects women of reproductive age. Gene and environmental factors are known to cause this disease . ${ }^{1}$ SLE is characterized by the formation of pathogenic autoantibodies against nucleic acids and their binding proteins caused by intolerance to the body's own components. The highest incidence of SLE is found in the United States of 23.2 / 100,000 population each year with prevalence 241 / 100,000 population. Rheumatology as outpatient clinic in several hospitals in Indonesia showed an increase in SLE patient visits by $17.9-27.2 \%$ (in 2015); $18.7-31.5 \%$ (in 2016); and 30.3-58\% (in 2017). The ratio of women and men is 15: 1 to 22: 1 . With a good initial approach, survival rate has increased globally over the past five decades, around 74.8 and $63.3 \%$ (in 1950) to 94.8 and $91.4 \% .^{2}$

A well-prepared pregnancy in SLE women has a favorable prognosis. ${ }^{1,3}$ However, we should aware of complications of SLE during pregnancy. Disease flares can occur during pregnancy. Preeclampsia and lupus nephritis are two conditions that can occur. Both conditions can be distinguished thorough careful examination. ${ }^{4}$

Hepatitis B virus (HBV) infection is a major health problem in the world in general, including Indonesia. It is estimated that more than 2 billion people has been exposed to HBV. Approximately, prevalence $\mathrm{HBV}$ in Indonesia 4-20.3\%. Reactivation of HBV replication complicated liver decompensation in immunosuppressed patients is reported to occur around $20-50 \%$ in patients with hepatitis B infection undergoing chemotherapy or immunosuppression. Pregnant hepatitis B patients whose treatment decisions must be adjusted according to their conditions and benefits. Due to the close relationship between the immune system and the hepatitis B virus (HBV) replication, it is essential to monitor patients with current or past HBV infection under any type of immunosuppression. ${ }^{5}$

\section{Case report}

A 30-year-old pregnant woman came to emergency department due to general weakness 3 days prior to admission. She felt weakness, headache, epigastric pain, nausea and blurred vision. There was no rash at her face, shortness of breath, joint pain and hair loss. She also did not feel increase of appetite or loss of weight. There was no history of diabetes mellitus, hypertension, cardiovascular disease, hyperthyroidism, nor abortion. She confessed had previous history of muscle ache, weakness, and hair fall on 2016. She was diagnosed with SLE, anemia and hepatitis B since 2016. Her disease progression was controlled with medication cyclosporine $2 \times 25 \mathrm{mg}$ tablet, methylprednisolon (MP) 8-8-0 mg tablet daily and lamivudin 1x100 mg tablet. Physical examination showed lethargic, blood pressure 180/100 
$\mathrm{mm} \mathrm{Hg}$, pulse 109 beats per minute, respiratory rate 20 times per minute, axillary temperature $36,70 \mathrm{C}$, weighed approximately 65 $\mathrm{kgs}$, and consciousness level was alert. Inspection from sclera was anemia. From abdominal examination, uterine fundal height at umbilicus, there was ballottement, fetal beats 12-1213 and no uterine contraction detected. Peripheral perfusion was warm and dry, minimal oedema in both legs and capillary refill time $<2$ seconds.

Her ultrasound showed placental fundal grade I with biparietal diameter 4,95 $\mathrm{mm}$ and fetal weight 349 grams as seen on 24 weeks pregnancy. She was diagnosed with SLE in pregnancy, G3 P2002 24-week with severe preeclampsia, anemia, chronic hepatitis B and intrauterine growth retardation (IUGR; estimated fetal weight 500 grams).

Patient then treated with $20 \%$ magnesium sulfate $1 \mathrm{gr} / \mathrm{h}$

Table 1. Parameter Basic Laboratory of Patient

\begin{tabular}{|c|c|c|}
\hline Variable & 2017 (1st time diagnosis) & June 1st ,2018 (24week pregnancy) \\
\hline \multicolumn{3}{|l|}{ Blood } \\
\hline Hemoglobin & $8.4 \mathrm{gr} / \mathrm{dl}$ & $7.7 \mathrm{gr} / \mathrm{dl}$ \\
\hline Leucocyte & $6070 / \mu \mathrm{L}$ & $6380 / \mu \mathrm{L}$ \\
\hline Platelet & $34.000 / \mu \mathrm{L}$ & $116.000 / \mu \mathrm{L}$ \\
\hline Erythrocyte Sedimentation Rate & & $22 \mathrm{~mm} / \mathrm{h}$ \\
\hline Ureum & & $12 \mathrm{mg} / \mathrm{dl}$ \\
\hline Creatinin serum & & $0.86 \mathrm{mg} / \mathrm{dl}$ \\
\hline Albumin & & $3.62 \mathrm{gr} / \mathrm{dl}$ \\
\hline Sodium & & $134 \mathrm{mmol} / \mathrm{L}$ \\
\hline Potasssium & & $3.7 \mathrm{mmol} / \mathrm{L}$ \\
\hline Chloride & & $98 \mathrm{mmol} / \mathrm{L}$ \\
\hline SGOT & & $117 \mathrm{U} / \mathrm{L}$ \\
\hline SGPT & & $11 \mathrm{U} / \mathrm{L}$ \\
\hline Uric acid & & $8.2 \mathrm{mg} / \mathrm{dl}$ \\
\hline Blood sugar & & $69 \mathrm{mg} / \mathrm{dl}$ \\
\hline \multicolumn{3}{|l|}{ Immunology Analysis } \\
\hline ANA & 9.62 (positive) & \\
\hline $\mathrm{C} 3$ & $63.1(\downarrow)$ & $116(\mathrm{~N})$ \\
\hline $\mathrm{C} 4$ & $24.4(\downarrow)$ & $36(\downarrow)$ \\
\hline Anti ds-DNA & & $5.6(\mathrm{~N})$ \\
\hline HBV DNA & & $1.78 \times 107$ copies/mL. \\
\hline Coombs test & & Negative for direct and indirect \\
\hline Treatment & Pulse dose methyl prednisolone $500 \mathrm{mg} 3$ days & \\
\hline \multicolumn{3}{|l|}{ Urine analysis } \\
\hline SG & & 1.015 \\
\hline $\mathrm{pH}$ & & 6.5 \\
\hline Glucose & & Negative \\
\hline Ketone & & +2 \\
\hline Bilirubine & & +2 \\
\hline Protein & & +4 \\
\hline Nitrite & & Negative \\
\hline Urobilinogen & & +2 \\
\hline Leucocyte & & $0-1 / \operatorname{lpf}$ \\
\hline Erythrocyte & & $5-10 / \operatorname{lpf}$ \\
\hline Bacteria & & Positive \\
\hline
\end{tabular}

intravenous injection, nifedipine $3 \times 10 \mathrm{mg}$ tablet $(\mathrm{BP}<$ $160 \mathrm{mmHg}$ ), methyldopa $3 \times 500 \mathrm{mg}$ tablet, cyclosporine $2 \times 100$ mg tablet, tenofovir $1 \times 300 \mathrm{mg}$ tablet, calcium $2 \times 500 \mathrm{mg}$, erythrocyte washed transfusion 2 bags/day until hemoglobin reached $\geq 9 \mathrm{gr} / \mathrm{dl}$. After one day evaluation, patient was planned for normal delivery. However, the baby was stillborn. At this time, intravenous methylprednisolone $1 \mathrm{mg} / \mathrm{kgBW}$ was given due to stress condition of delivery. She showed sign of improvement with supportive therapy.

Methylprednisolone was tapered to $0,5 \mathrm{mg} / \mathrm{kgBW}$ i.v. Then patient was discharged after 5 days. Signs and symptoms of preeclampsia has been completely resolved during follow-up visit. 


\section{Discussion}

Disease flares can occur during pregnancy, as well as in the several months prior delivery. ${ }^{6}$ Score of disease activity is needed to assess of SLE activity during pregnancy. According to the Lupus Activity Index in Pregnancy (LAI-P) score, clinical data were divided into 4 groups. Group 1 consist mild clinical symptoms, group 2 is internal organs involvement, group 3 includes modifications of treatment and group 4 to laboratory parameters. ${ }^{7}$ In this report, patient was diagnosed SLE since 2016. From anamnesis, clinical and laboratory examination, LAI-P Score of this patient (hematology 1 and immunosuppressive drug 3) was 1 . According to the score, she did not show any sign of lupus flares.

Preeclampsia defines blood pressure $>140 / 90 \mathrm{mmHg}$ and proteinuria $>300 \mathrm{mg} / 24-\mathrm{h}$ in urine after 20 weeks of pregnancy. To distinguish preeclampsia and active lupus nephritis is often subtle, since both condition may present with increasing proteinuria, hypertension, lower extremity oedema, and disruption in renal function. ${ }^{1}$ This patient had no history of hypertension before pregnancy nor before 20 weeks gestation. To distinguish lupus nephritis and preeclampsia, there were several symptoms from patients. Preeclampsia usually happens after 20 weeks of gestation, proteinuria $\geq 300 \mathrm{mg} / \mathrm{dl}$, no urine sediment, uric acid level $\geq 5,5 \mathrm{mg} / \mathrm{dl}$, stable ds DNA, and normal complement level. Thus we concluded that patient had sign of preeclampsia. Preterm birth may be the most common complication that can be encountered from mothers with SLE, because of prematurity lead to long-term medical complications and cause die soon after birth. Its disease activity it self during pregnancy increases the probability of preterm birth. Risk of having miscarriage and stillbirth are $3-16 \%$, IUGR $12,7 \%$, maternal lupus flare $25,6 \%$ and neonatal lupus syndrome $2 \%{ }^{8}$

Prevention of increasing SLE activity is important given its complications for both mother and baby. Medical drugs used in pregnancy should be in the safe category and should not need stopped. ${ }^{8}$ Glucocorticoids, mainly in the form of prednisolone, is usually safe for pregnancy. Azathioprine and hydroxychloroquine are immunosuppressant agents classified as safe for pregnancy.

Reactivation of HBV replication could be mediated by suppression of immune by glucocorticoid element. Its reactivation by liver decompensation in immunosuppressed patients is reported in $20-50 \%$ of patients with chronic HBV infection undergoing chemotherapy or immunosuppression. Although the incidence of reactivation in HBV patients receiving immunosuppressant therapy is unclear, a study reported that HBV reactivation occurred in about $72 \%$ of patients receiving prednisolone compared to $38 \%$ who did not $(\mathrm{p}=0.02){ }^{9}$

A woman in reproductive age without advanced fibrosis who plans a pregnancy may delay antiviral until delivery. Pregnant women with hepatitis B chronic and advanced fibrosis or cirrhosis, therapy with tenovofir is recommended. Pregnant women whom already on nucleoside analogue treatment, tenofovir could be continued yet entecavir or other nucleosides analogue must be switched to tenofovir. All pregnant women with high HBV DNA levels (200,000 $\mathrm{IU} / \mathrm{ml}$ ) or HBsAg levels $4 \log 10 \mathrm{IU} / \mathrm{ml}$, antiviral prophylaxis with tenofovir disoproxil fumarate (TDF) should start at 24-28 week of gestation and continue for up to 12 weeks after delivery. ${ }^{10,11}$ In our case, patient was switched from lamivudine to tenofovir due to failure of viral suppression.

\section{Conclusion}

Pregnancy and SLE is a never ending loop both. Pregnancy in SLE should be well planned so that any complication can be prevented. Awareness of disease activities and initial management could save lives. The use of antivirus is the right step to prevent the reactivation of viral replication in hepatitis B patients with immunosuppressants. Immunoglobulin is highly recommended for newborn from mothers with HBV infection.

\section{Conflict of Interest}

The author stated there is no conflict of interest

\section{References}

1. Stojan G, Baer AN. Flares of systemic lupus erythematosus during pregnancy and the puerperium: Prevention, diagnosis and management. Expert Rev Clin Immunol. 2012;8(5):439-53.

2. Perhimpunan Reumatologi In. <SLE lupus 100.pdf>. 2019. Jakarta: Perhimpunan Reumatologi Indonesia; Indonesia.

3. Yang MJ, Chen CY, Chang WH, Tseng JY, Yeh CC. Pregnancy outcome of systemic lupus erythematosus in relation to lupus activity before and during pregnancy. J Chinese Med Assoc [Internet]. 2015;78(4):235-40. Available from: http://dx.doi.org/10.1016/j. jcma.2014.11.008

4. Ruiz-Irastorza G, Khamashta MA. Evaluation of systemic lupus erythematosus activity during pregnancy. Lupus. 2004;13(9):679-82.

5. Gonzalez SA, Perrillo RP. Hepatitis B Virus Reactivation in the Setting of Cancer Chemotherapy and Other Immunosuppressive Drug Therapy. Clin Infect Dis. 2016;62(May):S306-13.

6. Knight CL, Nelson-Piercy C. Management of systemic lupus erythematosus during pregnancy: Challenges and solutions. Open Access Rheumatol Res Rev. 2017;9:37-53.

7. Olesińska M, Więsik-Szewczyk E, Chwalińska-Sadowska H. Evaluation of systemic lupus erythematosus activity during pregnancy. Polish Arch Intern Med. 2018;117(7):312-6.

8. Cauldwell M, Nelson-Piercy C. Maternal and fetal complications of systemic lupus erythematosus. Obstet Gynaecol. 2012;14(3):167-74.

9. Terrault NA, Bzowej NH, Chang KM, Hwang JP, Jonas MM, Murad MH. AASLD guidelines for treatment of chronic hepatitis B. Hepatology. 2016;63(1):261-83.

10. Lampertico P, Agarwal K, Berg T, Buti M, Janssen HLA, Papatheodoridis G, et al. EASL 2017 Clinical Practice Guidelines on the management of hepatitis B virus infection. J Hepatol. 2017;67(2):370-98.

11. Idilman R. The summarized of EASL 2017 Clinical Practice Guidelines on the management of hepatitis B virus infection. Turkish J Gastroenterol. 2017;28(5):412-6. 